\title{
Research Paper: The Relationship Between Fine Motor Skills and Social Development and Maturation
}

\author{
Leila Dehghan ${ }^{1}$, Navid Mirzakhani ${ }^{1 *}$, Mehdi Rezaee ${ }^{1}$, Mehdi Tabatabaee $^{2}$
}

1. Department of Occupational Therapy, School of Rehabilitation, Shahid Beheshti University of Medical Sciences, Tehran, Iran

2. Department of Biostatistics, School of Allied Medical Sciences, Shahid Beheshti University of Medical Sciences, Tehran, Iran.

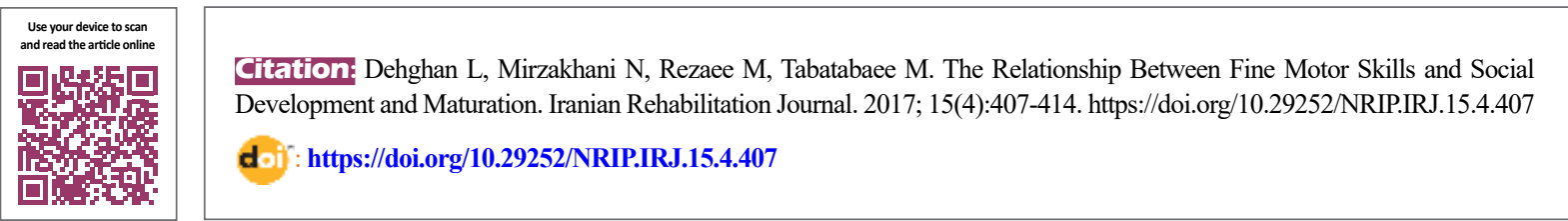

Article info:

Received: 13 May 2017

Accepted: 01 Sep. 2017

Keywords:

Motor skills, Social development, Children

\section{ABSTRACT}

Objectives: Social development in children is influenced by several factors, including family, school friends, television, gender, race, socioeconomic status, and locomotor activity, and depending on the situation and how they react to it, social development and maturity might get accelerated or get undermined. Therefore, in this study, we aimed to investigate the relationship between fine motor skills and social development and maturity in children.

Methods: This is a descriptive-analytical study that included 85 children in the age group of 6-8 years ( 41 boys and 44 girls). We used a two-stage random sampling method in order to select samples from elementary schools in Regions 14 and 15, Tehran. Information was collected through the General Health Questionnaire and demographic questionnaire, which was filled by the parents. Fine motor skills test consisting of three subtests, i.e. response speed, visual-motor control, and upper-limb speed and dexterity, was measured using BruninksOseretsky Test of Motor Proficiency. Social maturity was measured using Vineland social maturity scale. The entire process lasted for a month and the mean, standard deviation, range of changes, minimum, and maximum values were analyzed. Mann-Whitney test was used to compare mean scores of variables between male and female groups and significance level for statistical tests was analyzed at $\alpha=0.05$.

Results: Significant correlation between social quotient and total score of fine motor skills variable was obtained $(\mathrm{P}<0.001, \mathrm{r}=0.46)$. A significant correlation was also observed between visual-motor control score and social quotient $(\mathrm{P}<0.001, \mathrm{r}=0.44)$ and between social quotient and upper-limb speed and dexterity $(\mathrm{P}<0.001, \mathrm{r}=0.36)$. However, there was no significant correlation observed between response speed and social quotient $(\mathrm{P}<0.42, \mathrm{r}=0.08)$.

Discussion: According to the results, there is a significant association between fine motor skills with respect to visual-motor skills of hands and social competence and maturity in children. As a result, fine motor skill can be used as an important factor along with other effective factors in improving social skills of children who have defects in the social field

* Corresponding Author: 


\section{Introduction}



ocial skills and effective communication are essential factors in order to have a successful life. Social skills reflect factors such as culture, social groups, family, lifestyle, and close relatives; these skills, play an important role in an individual's behavior and his social health [1]. In fact, social skills can be developed through successful social interactions, by gaining appropriate social understanding, and by enabling themselves to select suitable solutions to different problems that come in their way of reaching their goals and attaining independence. In order to be independent in life, appropriate social skills along with other essential life skills are required.

Vidoni specified in his article that fine motor skills are needed in most everyday activities, such as dressing, eating, and playing, and that these skills are achieved by the maturation of the central nervous system and specific motor experiences [2]. Stronger connections between the two cerebral hemispheres and the cerebellum lead to better fine motor skills. These stronger connections guarantee learning and optimization of brain functions, leading to more effective social interactions [3]. Hand movement skills can be considered an important factor in the development of social relationships. These skills can be improved by exercising and learning basic motor patterns [4].

$\mathrm{Yu}$ and Smith in their study mentioned that there are strong relationships between fine motor skills, learning ability, and communication skills. These findings indicate that there is a strong relationship between functions of the cerebellum and functions of the brain, which are closely related to learning and social behavior [5]. Cho et al., mentioned the adverse effects of motor problems, especially fine motor problems, in the childhood that can cause problems in social and academic (school) competence. Indeed, children with motor problems avoid physical activities thereby causing obesity, social communication disorders, low self-esteem, and poor academic performance [6].

Social behaviors form people's everyday lives and social interaction leads to other aspects of human development. Social development occurs as a result of child interacting with his/her social environment; it is a process that enables the child to understand and anticipate the behaviors of others and control/regulate his/her own behaviors accordingly [7]. In a study on the importance of social growth in Iranian society, Zarei specified that incompatibility, irresponsibility, lack of observing social norms, and poor cooperation of the young individuals are among the major concerns discussed in various scientific contexts. He continued that the lack of adaptability of this population is due to their poor socialization and social immaturity. Moreover, issues such as high levels of aggression and individualism indicate that the Iranian young people do not have the necessary and adequate level of social development; thus, social growth and development must be studied as one of the major social issues in the Iranian society [8].

Different aspects of social development can be observed in people's social behavior, social skills, and social relationships. Social development is influenced by various factors, including verbal and nonverbal skills, social understandings, and motor skills. Along with other factors, adaptive behavior is a very important factor that determines a child's social maturity [9]. Adaptive behaviors are shaped through maturity, learning, and social harmony [10]. These behaviors are shaped during the childhood. Human development during the childhood has different social, emotional, cognitive, and physical aspects that must be considered; otherwise, the child grows up vulnerable and with serious mental problems [11].

Richman and Valendezdan studied elementary school children and specified that parenting style is an important factor affecting the development of adaptive behaviors in children; parenting style is in fact among the most important factors in the formation of a child's behavioral system and his/ her social maturity [12]. Adaptive behavior is of particular importance in the development of a child [10]. Education positively affects a child's emotional maturity and decreases his/her emotional or behavioral problems [9]. Meanwhile, parents and family members and their home environment can play important roles in preparing the child for learning and education so that the child is prepared for normal development of social skills through training appropriate coping behavior. In fact, children who have not been prepared for education in their home environments may experience problems in the development of adaptive behaviors, and this can result in serious social problems such as inadequate mobility, weak social bonds, and maladaptive behaviors [13].

According to the social information processing theory, motor experiences play a significant role in people's social development [14]. Among an individual's motor skills, his/her fine motor skills (i.e. coordination between eyes and hands) are of great importance. Since factors such as mental and emotional conditions, family conditions, learning, and so on are involved in social functioning, in this study, we tried to apply identical conditions by randomly selecting samples and by conducting general health test in order to ensure the input factors are met. 
In addition, because there are less number of studies on the impact of fine motor skill with respect to social functioning, this study addresses this issue so that disorders such as autism, motor delay, and so on can be treated in a better manner, and that the results of this study can be used a part of medical intervention. Thus, in this study, we aimed to investigate and measure the relationship between fine motor skills and social skills in children.

\section{Methods}

We used a descriptive analytical research methodology in which 85 children participated. Their mean $( \pm \mathrm{SD})$ age was $6.65( \pm 0.84)$ years. Of the 85 participants, 44 were female, and their mean $( \pm \mathrm{SD})$ age was $6.05( \pm 0.73)$ years, and 41 were male, and their mean age was $6.82( \pm 0.92)$ years. Research samples were selected using random two-stage sampling method from elementary schools in Regions 14 and 15, Tehran, during the academic year 2015-2016. That is, in the first stage, random cluster sampling was performed for the selection of elementary schools, one of which was girl's school and the other one was boy's school. Then, in the second stage, simple random sampling was performed in each school. In the girl's school, four students were randomly selected from a population of 100 students in the age group of 6-8 years. In the boy's school, 41 students were randomly selected from a population of 150 students in the age group of 6-8 years. In order to determine sample size, considering $\alpha=0.05, \beta=0.2$, and $r=0.3$, following equation was used, and it was calculated as 85 for this study.

$$
n=\frac{(Z \alpha+Z \beta)^{2}}{\left(0.5 \ln \frac{1-r}{1+r}\right)^{2}}+3
$$

The following inclusion criteria were considered for selection: age in the range of 6-8 years, having a normal Intelligence Quotients ${ }^{1}$ (IQ), not having any of underlying diseases, and not using psychiatric medications. The exclusion criteria were the child's inability to complete the questionnaires and lack of cooperation due to unacceptable causes. The data collection process started when parents completed the demographic questionnaire.

Then, the children completed the General Health Questionnaire (GHQ). It took about 20 minutes for the children to complete the GHQ in a quite $3 \times 3$-square meter school room with a table and two chairs (all tests were performed under the supervision of the same individual). Then, those who met the inclusion criteria entered the study and completed the Bruninks-Oseretsky Test of

1. IQ=90-110; Every accepted child in public elementary schools has a normal IQ, because all children are tested before being enrolled in Iran's public elementary schools.
Motor Proficiency (BOTMP). In order to test fine motor skills of the examined participants, only their fine motor composite scores were collected. It took 30-40 minutes for all the participants to complete the Fine Motor Composite part of the BOTMP. Finally, all the participants completed the Vineland Social Maturity Scale (VSMS) based on their age groups. This part took 10 minutes to be completed. The whole process of data collection took 80 minutes for each participant.

\section{Instruments}

The following data collection tools were used in this study:

\section{The General Health Questionnaire (GHQ)}

GHQ was used to ensure general health of the participants. This scale consists of four subscales: 1. Somatic symptoms, including feelings about general health status along with fatigue and somatic symptoms associated with emotional arousal; 2. Anxiety/insomnia, including questions examining anxiety and sleep disorders; 3. Social dysfunction, including questions covering the ability to cope with daily and occupational desires; and 4. Severe depression including questions scrutinizing severe depression and suicidal ideations. Accordingly, each participant obtains five different scores, four for the GHQ subscales and one for the overall GHQ score, which is the sum of scores of its four subscales.

The questionnaire is scored on a 4 point Likert scale ranging from 0 (not at all) to 3 (much more like than usual). Dadsetan, in his study, considered university students whose GHQ scores were one SD above the mean (i.e. 42) and who were prone to psychological problems. Accordingly, the higher the GHQ scores the poorer the psychological well-being of the subjects. The validity and reliability of the GHQ have been confirmed in various studies. For example, in a study entitled "Standardization of the General Health Questionnaire among students in Teacher Training Centers", Dasteji reported a reliability coefficient of 0.84 for the GHQ. In another study, entitled "Analysis of children's behaviors and parents' mental health in polygamous families", Mojahed reported a test-retest reliability coefficient of 0.62 , confirming the reliability of the GHQ [15].

\section{Bruninks-Oseretsky Test of Motor Proficiency (BOTMP)}

The BOTMP has been introduced as a useful tool in the diagnosis and evaluation of treatment outcomes, especially in occupational therapy clinics [16]. It has 48 items 
assessing eight subscales. The administration of this test takes 100-120 minutes [17]. Four of the BOTMP subscales (i.e. 20 items) provide the gross motor composite score; three (i.e. 17 items) provide fine motor composite score; and one (i.e. 9 items) provides the upper-limb coordination score. The BOTMP subscales assessing fine motor skills are response speed (RS) (1 item), VisualMotor Control (VMC) (8 items), and Upper-Limb Speed and Dexterity (ULSD) ( 8 items). Bruninks et al., have confirmed validity and reliability of the BOTMP $[18$, 19]. In Iran, Mousavi et al., examined validity and reliability of the BOTMP and reported a reliability coefficient of 0.78 [20].

\section{Vineland Social Maturity Scale (VSMS)}

The VSMS is an evolutionary scale measuring a person's ability to meet his/her daily needs and to take responsibility for his/her behaviors. In other words, it measures social maturity and competence. It includes the age range from birth to 25 years. For the age range from birth to 12 years, there are different sets of VSMS questions for each year, but there are similar questions in the case of age range from 12-15, 15-18, 18-20, and 20-25, and above 25 years. It has been specified that the results of VSMS are more reliable for younger samples. Each item provides information not only through the written content, but also through interviews with parents, nurses, sisters, or any person who knows the child well. This test can also be completed based on the examiner's observations.

It examines the extent to which a child can perform his/ her daily duties normally and independently. Accordingly, the items are divided into eight subdomains of general self-help, self-help in eating, self-help in dressing, selfdirection, engagement, verbal communication, displacement, and socialization. According to the overall VSMS score, social age and Social Quotient ${ }^{2}$ (SQ) can be measured for each child. When scoring the VSMS items, a "+" sign indicates that the child has performed the task successfully and a "-" indicates that the child has failed to perform the task successfully.

A "no+" sign indicates that the child has not had the opportunity to perform the task, but he/she has the ability to complete the task. If the "no+" is inserted between two "+" signs, one point will be calculated, and if it is inserted between "+" and "-" signs, half a point will be considered for that item. However, if the "no+"sign is located between two "-_ signs, no point will be considered. A " $\mathrm{f}+$ " sign indicates that the child has had a problem when performing the task, but he/she is able perform

2. SQ: Social age/calendar age*100 it generally. For items with a "f+" sign, one point will be considered. The "-f)" sign indicates that the child is naturally unable to perform the task due to some substantial problem (e.g. having a mutilated hand or foot). Finally, the " \pm " sign indicates that the child is able to perform the task occasionally; thus, items scored with a " \pm " sign have half a point [21]

In a study, Larijani examined the reliability and validity of the VSMS among 620 participants of different age groups. He reported a test-retest reliability of 0.92 for the overall test. The time interval between different administrations of the test ranged between 1 day and 9 months [22]. In another study, Zadshir et al., reported a Cronbach's alpha of 0.68 for the total scale [22].

\section{Statistical analysis method}

Mean, SD, range of changes, minimum, and maximum were used in statistical analysis of descriptive variables, and Spearman correlation coefficient was used to determine correlation between SQ and total score of fine motor skills, RS, VMC, and ULSD. Mann-Whitney test was used to compare mean scores of variables between male and female groups and significance level for statistical tests was considered to be $\alpha=0.05$. We used SPSS v. 23 software for the data analysis.

\section{Moral considerations}

All moral considerations subject has been considered according to the international law and legislated by the ethics committee.

\section{Results}

Table 1 shows demographic characteristics of the sample group. As shown, 44 participants were female with a mean $( \pm \mathrm{SD})$ age of $6.05( \pm 0.73)$, and 41participantswere male with a mean age of $6.82( \pm 0.92)$. Mean $( \pm S D)$ of total variables of SQ, RS, VMC, and ULSD were found to be $10.34 \pm 2.46,10.67 \pm 3.63,19.56 \pm 4.09,5.97 \pm 3.37$, and $40.80 \pm 11.85$, respectively. Spearman correlation coefficient was used to measure relationship between $\mathrm{SQ}$, VMC, ULSD, and total score of fine motor skills, due to rank data. Data in Table 2 indicate that there is a significant relationship between SQ and subscales of ULSD, $\mathrm{VMC}$, and total score of fine motor skills ( $\alpha=0.05$ for all of these variables). However, no significant relationship was observed between SQ and subscale of RS $(\mathrm{P}=0.42)$.

Mann-Whitney test was used to compare mean scores of variables of RS, VMC, ULSD, total score of fine 


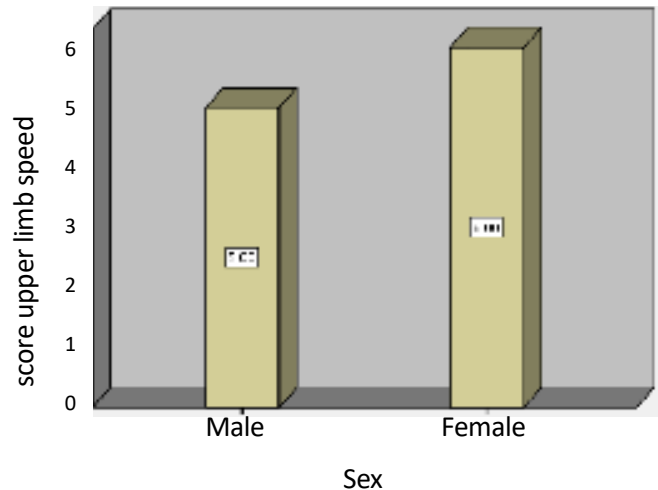

Mranlan Rkehabolltation Journa

Figure 1. Comparison of upper limb speed and dexterity between males and females

motor skills, and SQ between male and female groups. Data in Table 3 indicate that no significant difference was observed between mean total scores of fine motor skills score, SQ, and VMC. In other variables, significant difference was observed between mean score of RS and ULSD score in two groups. In Figures 1 and 2, the configuration of comparison between ULSD and RS between males and females has been shown.

\section{Discussion}

The results of statistical analyses and calculation of correlation coefficients showed a significant linear relationship between $\mathrm{SQ}$ and the total FMC score $(\mathrm{P}<0.01$ for all

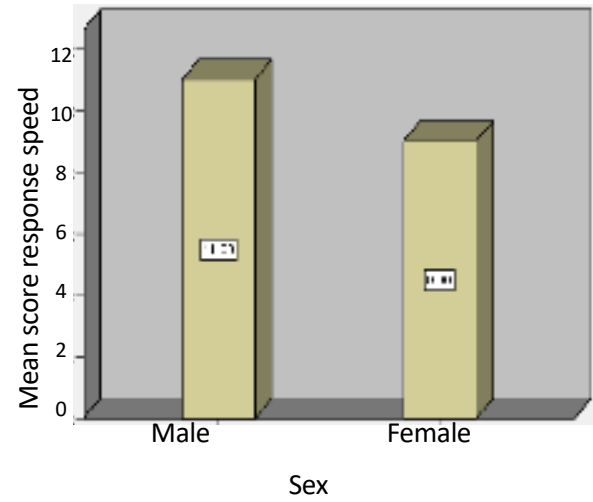

Iranlan Rehabolltotton Journal

Figure 2. Comparison between response speed between males and females

test \& $\mathrm{P}<0.001$ for FMC). This finding was not consistent with results of a study conducted by Case-Smith on 30 pre-elementary school children with motor skill developmental delays. In fact, she found weak relationships between fine motor skills and self-help skills, mobility, and social interactions. However, she specified that those weak relationships could be caused by differences in environmental, cultural, and judgmental issues [23].

However, Tabatabai in a paper entitled "Relationship between motor growth and social growth in autistic children" found that there is a significant relationship between fine motor skills and social development [24]. The results of this study are also in line with the results

Table 1. Mean and SD of variables of age, response speed, visual motor control, upper-limb speed and dexterity, total score of fine motor skills and social quotient $(\mathrm{n}=85, \mathrm{P}<0.01)$

\begin{tabular}{|c|c|c|c|c|c|c|c|}
\hline Variable & Range & Maximum & Minimum & SD & Mean & No. & Group \\
\hline & 3.60 & 8.07 & 5.01 & 0.73 & 6.05 & 44 & Girls \\
\hline \multirow[t]{2}{*}{ Total } & 3.60 & 8.07 & 5.01 & 0.92 & 6.82 & 41 & Boys \\
\hline & 3.60 & 8.07 & 5.01 & 0.84 & 6.65 & 85 & Total \\
\hline Upper limb speed & 21 & 23 & 2 & 3.63 & 10.67 & 85 & Total \\
\hline $\begin{array}{l}\text { Visual motor } \\
\text { control }\end{array}$ & 27 & 29 & 2 & 4.90 & 19.57 & 85 & Total \\
\hline $\begin{array}{l}\text { Upper limb speed } \\
\text { \& dexterity }\end{array}$ & 13 & 14 & 1 & 3.37 & 5.97 & 85 & Total \\
\hline $\begin{array}{l}\text { Total score of fine } \\
\text { motor skills }\end{array}$ & 80 & 60 & -20 & 11.85 & 40.80 & 85 & Total \\
\hline Social quotient & 12.82 & 16.66 & 3.84 & 2.46 & 10.34 & 85 & Total \\
\hline
\end{tabular}

Mranlan Rehabolltation Journal 
Table 2. Spearman correlation distribution among variables of response speed, visual motor control, upper limb speed and dexterity and total score of fine skills with social quotient with $\mathrm{n}=85$ and $\mathrm{P}<0.01$

\begin{tabular}{|c|c|c|}
\hline \multirow{2}{*}{ Variable } & \multicolumn{2}{|c|}{ SQ } \\
\hline & Correlation Value & $\mathbf{P}$ \\
\hline Response speed & 0.088 & 0.42 \\
\hline Visual motor control & 0.448 & 0.001 \\
\hline Upper limb speed \& dexterity & 0.368 & 0.001 \\
\hline Total score of fine motor skills & 0.46 & 0.001 \\
\hline
\end{tabular}

Table 3. Comparison between mean scores of response speed, visual motor control, upper limb speed and dexterity, total score of fine motor skills, and social quotient in male and female groups

\begin{tabular}{ccccc}
\hline Variable & Gender & No. & Mean & P \\
\hline Response speed & Female & 41 & 49.62 & 0.01 \\
Visual motor control & Male & 44 & 36.83 & 0.23 \\
& Female & 41 & 46.29 & 0.04 \\
Upper limb speed \& dexterity & Male & 44 & 39.93 & 0.47 \\
Total score of fine motor skills & Female & 41 & 37.46 & 0.48 \\
\hline
\end{tabular}

of the study conducted by Kim et al., in which children with less motor problems were better socially mature, whereas those who had more severe motor problems were less socially mature [25]. In this regard, Hsu Hc et al., showed that autistic children who were socially well developed had also higher motor skills and more developed verbal and self-help skills compared to those who were not socially well developed [26]. One of the reasons behind this finding is that problematic fine motor activities can result in difficulties in the achievement of academic skills and increased levels of anxiety and depression in children [27].

The other finding of this study was a significant linear relationship between SQ and VMC $(\mathrm{P}<0.001)$. In line with our results, Tavakoli found that visual problems negatively affect children's cognitive and emotional development by limiting the range of their motor experiences. Therefore, visual impairments can lead to shortcomings in children's personality and social development by limiting their access to their environment; this lack of access to the environment can create feelings of incompetence, dependency, low self-esteem, and emotional problems in children [28]. Indeed, every dimension of the visual system (i.e. visual perception, spatial visualization, visual acuity, etc.) plays an important role in motor functions and behavioral patterns. In this regard, Umphred indicated that children need to process visual information in order to perform their everyday tasks efficiently. He further explained that impaired visual perception leads to difficulties in performing everyday tasks, such as eating, wearing clothes, social interactions, and engagements [29].

Therefore, it can be concluded that there is a significant relationship between visual problems and social development, which was also a finding of this study. The other finding of this study was a significant linear relationship between SQ and ULSD $(\mathrm{P}<0.001)$, which is consistent with the findings of the study conducted by Bonab et al., on hyperactive students. They reported that hyperactive children obtained significantly lower scores in fine motor skills, gross motor skills, and bilateral organ align- 
ment skills compared to normal children. They found a direct relationship between social acceptability and motor skills, indicating that low levels of motor skills' speed lead to low levels of social participation and self-esteem. They also reported that the speed of one-way and twoway hand movement was significantly lower in overactive children and this was the reason behind their poorer performance in motor activities including ULSD and RS that negatively affected their self-esteem and social relationships [30].

Thus indeed there is significant relationship between upper-limb speed and dexterity and social skills in children, which is inconsistent with findings by the current research, i.e. Lack of relationship between social quotient and upper-limb speed and dexterity $(\mathrm{P}<0.42)$. because the present study was conducted on healthy children. Moreover, ULSD subscale used in this study measured how rapidly the children responded to a moving visual stimulus, whereas other subscales measured fine motor skills. In fact, performing fine motor activities requires more precision and delicate activities. Thus, a child needs to focus hard in order to finish a fine motor activity successfully, making the child ready for learning and better social behaviors. Nonetheless, tasks measuring the RS of upper-limbs to a stimulus require less precision. It can be stated that actually social functioning and fine motor skills both have such nature (their neural system structure and function) that can involve wide parts of brain; thus, these variables can be interlinked.

\section{Conclusions}

Results of this study indicate that there is correlation between SQ and fine motor skills in typical children, which is consistent with the findings of other studies, i.e. the better the fine motor skills of the child is, higher will be his/her SQ and slower the functioning of the child with respect to fine motor skills, poorer will be his/her social skills. Indeed this relationship can be used in favor of improvement of social skills in children. Accordingly, children's social skills can be developed by helping them improve their fine motor skills. Undoubtedly, more developed social skills lead to higher levels of social maturity, more efficient self-help skills, and even better academic performance in children.

Following are some of the limitations of this study: 1 . Limitation in time, as students were to be studied within two months, and summer holidays arrived during the conduct of this study and access to the children was difficult; and 2. Planning had to be done in such a way that the child's classes were not missed, for example, those children with fewer course involvement were tested as priority.

Weakness of this paper was in one of subtests of Oseretsky tests, i.e. RS. As this subtest was not much related to our variable, fine motor skill measurement, and finally no relationship between this subtest and social skill was observed. Strength of this test was that despite differences in the sample population, relationship was found between fine motor skill and SQ, and access to samples was easier since it was performed in school.

\section{Acknowledgments}

This article is derived from a master thesis in Occupational Therapy, written by Ms. Dehghan. Hereby, we thank all professors who helped us in this research. We also express our gratitude to authorities in Shahid Beheshti University of Medical Sciences.

\section{Conflict of Interest}

The authors declared no conflicts of interest.

\section{References}

[1] Garma Roudi GhR, Vahdani Nia MS. [Social health: An investigation into social skills among students (Persian)] Payesh. 2006; 5(2):147-53.

[2] Vidoni ED, McCarley JS, Edwards JD, Boyd LA. Manual and oculomotor performance develop contemporaneously but independently during continuous tracking. Experimental Brain Research. 2009; 195(4):611-20. doi: 10.1007/s00221-009-1833-2

[3] Elison JT, Paterson SJ, Wolff JJ, Reznick JS, Sasson NJ, Gu $\mathrm{H}$, et al. White matter microstructure and atypical visual orienting in 7-month-olds at risk for autism. American Journal of Psychiatry. 2013; 170(8):899-908. doi: 10.1176/appi. ajp.2012.12091150

[4] Ali Abadi A. Assesment of relationship between the ability in test of distinguish two points and the hand writing skill in second grade elementary students in regions $8 \& 13$ of Tehran education, in college of rehabilitation sciences iran university of medical sciences (Persian)] [MSc. thesis]. Tehran: Iran University of Medical Sciences; 2001.

[5] Yu C, Smith LB. Joint Attention without Gaze following: Human infants and their parents coordinate visual attention to objects through eye-hand coordination. PLoS ONE. 2013; 8(11):e79659. doi: 10.1371/journal.pone.0079659

[6] Cho H, Ji S, Chung S, Kim M, Joung YS. Motor function in school aged children with attention deficit/hyperactivity disorder in Korea. Psychiatry Investigation. 2014; 11(3):223. doi: 10.4306/pi.2014.11.3.223 
[7] Rahnama A, Ellieen H. [Comparison of social growth in Shahed and non-Shahed students in Tehran (Persian)]. Daneshvar-e Raftar. 2005; 12(15):33-44.

[8] Zarei A, Hasani K. [Study the family influence on social development of students in Kermanshah (Persian)] [Internet] 2005. Available from: https://amoozak.org/sites/default/ files/article/social-development_0.pdf

[9] Daramadi PS. [Psychological Foundation of Education of mentally retarded children (educable and capable of being trained) (Persian)]. Tehran: Orooj Pub; 1994.

[10] Davar Manesh A. Rehabilitation training of mentally handicapped children. Tehran: University of Social Welfare and Rehabilitation Sciences. 2006.

[11] Shafiabady A. [Child guidance and conselling (concepts and applications) (Persian)]. Tehran: SAMT; 2008.

[12] Navvabinejad Sh. [Three discourses on guidance and education of children (Persian)]. Tehran: Jazil Publication; 2001.

[13] Masen PH, \& Kagan J, Boston AC, Conger JJ. Growth and personality of child [M. Yasaii, Persian trans]. Tehran: Markaz Publication; 1990.

[14] Haywood K, Getchell N. Life span motor development. New York: Human Kinetics; 2014

[15] Mobasher Moghadam N. [The relationship between employment and mental health of married and non-married students in Alzahra University (Persian)] [MSc. thesis]. Tehran: Alzahra University; 2003.

[16] Wilson BN, Polatajko HJ, Kaplan BJ, Faris P. Use of the Bruininks-Oseretsky Test of motor proficiency in occupational therapy. American Journal of Occupational Therapy. 1995; 49(1):8-17. doi: 10.5014/ajot.49.1.8

[17] Soltani Khadive K, Kamali.M, Rafiee.Sh, Taghizadeh Gh. [Assessment of correlation between Bruininks oseretsky test of motor proficiency (BOTMP) and Peabody developmental motor scale in the evaluation of motor skills in Educable children with intellectual disability (Persian)]. Research in Rehabilitation science; 2014; 10(6):306-314.

[18] Bruninks R. Bruninks Oseretsky test of motor proficiency: Examiners manual. Minnesota: American Guidance Service; 1978.

[19] Hattie J, Edwards H. A review of the Bruininks Oseretsky test of motor proficiency. British Journal of Educational Psychology. 1987; 57(1):104-13. doi: 10.1111/j.2044-8279.1987. tb03065.x

[20] Dana A, Asgari F, Hashemi M. Description of gross and fine motor skills for 9 and 10 years old children of Golestan province and comparison to each other. Middle East Journal of Scientific Research. 2011; 8:401-6.

[21] Anastasi A. Psychological testing. New York: Macmillan Publishing Company; 1990.

[22] Zadshir F, Stoki M, Emamipour S. [Comparison of students moral judgment and social development in student: Invendiqating the role of teaching the holy Quran by memorization in independent schools in Tehran (Persian)]. Journal of Applied Psychology. 2009; 3(2-10):25-47.
[23] Case Smith J. The relationships among sensorimotor components, fine motor skill, and functional performance in preschool children. American Journal of Occupational Therapy. 1995; 49(7):645-52. doi: 10.5014/ajot.49.7.645

[24] Tabatabaee S, Shahbazi M, Bagherzadeh F. [The relationship between motor development and social development of children in 6 to 10 years old in Mashhad (Persian)]. Development \& Motor Learning. 2016; 8(2): 209-24.

[25] Kim H, Carlson AG, Curby TW, Winsler A. Relations among motor, social, and cognitive skills in pre-kindergarten children with developmental disabilities. Research in Developmental Disabilities. 2016; 53-54:43-60. doi: 10.1016/j. ridd.2016.01.016

[26] Hsu HC, Chen CL, Cheng PT, Chen CH, Chong CY, Lin YY. The relationship of social function with motor and speech functions in children with autism. Chang Gung Medical Journal. 2004; 27(10):750-7. PMID: 15646298

[27] Gaul D, Issartel J. Fine motor skill proficiency in typically developing children: On or off the maturation track. Human Movement Science. 2016; 46:78-85. doi: 10.1016/j.humov.2015.12.011

[28] Tavakoli E. [Explaining the social development of children with visual impairment problems from the perspective of attachment (Persian)]. Exceptional Education. 2015;3(131):57-64

[29] Umphred DA, Lazaro R. Neurological rehabilitation. New York: Mosby; 2012.

[30] Sepehri Bonab H, Ebrahimi Sani S. The comparison of gross and fine motor skills between attention deficit hyperactivity disorder and normal students. Journal of Instruction and Evaluation. 2008; 1(14):131-45. 